MULTIPLE REVIEW OF

Imagination and Convention

By Ernie Lepore \& Matthew Stone

\title{
Linguistic Conventions and the Role of Pragmatics
}

\section{Robyn Carston}

\section{Main claims and the question that arises}

As reflected in the title of their book, Ernie Lepore and Matthew Stone maintain that there are two ways in which language productions (spoken or written) can engage our minds. On the one hand, there are linguistic conventions, which are entirely responsible for the public propositional content that our utterances convey, so grasping that content is a matter of knowing the relevant conventions. These contents are entered on the conversational scoreboard, which keeps a record of our meaning-making and the constraints on it. ${ }^{1}$ On the other hand, certain uses of language call for an (often open-ended) imaginative engagement with the imagery of an utterance; these include various kinds of figurative uses of language, certain evocative literal uses, and cases of 'invited inference'. This kind of activity has an essentially private significance; although interlocutors may end up sharing insights by this means, those are not components of the public meaning-making endeavour.

I am grateful to Emma Borg for helpful comments on an earlier draft of this review.

Address for correspondence: UCL Linguistics, Chandler House, 2 Wakefield Street, London WC1N 1PF, UK. Email: robyn.carston@ucl.ac.uk

1 The notion of convention employed is that of Lewis (1969) and the metaphor of the 'conversational scoreboard' is from Lewis (1979). 
The following question arises: where is pragmatics in this account of linguistic communication? The first of the two modes of linguistic engagement given above constitutes semantics, a social convention-bound competence. The second is something else altogether (neither a matter of semantics nor pragmatics), a much less regulated, more exploratory, range of inferential and associative processes. Lepore and Stone's account boldly and provocatively argues that the long-standing Gricean, neo-Gricean and relevance-theoretic pragmatic accounts of utterance interpretation and thus of the semantics-pragmatic distinction are all quite mistaken. Lepore and Stone (henceforth $L \& S$ ) have a very expansive view of semantics: 'Interlocutors are normally coordinating on a process of inquiry, through which they commit to make their meanings public. Semantics, we suggest, describes the social competence that specifically supports this coordinate inquiry' (p.256) and a very diminished view of pragmatics: 'Pragmatics merely disambiguates; pragmatic reasoning never contributes content to utterances.' (p.83, and reiterated throughout). So linguistic conventions provide all the content that the speaker is presenting for public meaning consumption and, in cases where the language provides more than one meaning convention for a word or a structure in the utterance, pragmatics has the role of selecting among them. Furthermore, the pragmatics involved doesn't appeal to anything like Grice's Cooperative Principle and conversational maxims, or to anything like the cognitively-based 'presumption of optimal relevance' which drives utterance interpretation in Sperber \& Wilson's (1995) Relevance Theory (RT). Rather: '[It] typically exploits shallow cues rather than deep inferences about the speaker's mental state' (p.265). The idea is that disambiguation is a matter of finding a coherent interpretation on the basis of familiar patterns of language usage and salient contextual factors; it is not governed by any principles or presumptions specific to ostensive communicative behaviour and is not geared to the recovery of a speaker's m-intention (Grice) or communicative intention (Sperber \& Wilson). 
It is a great strength of the book that it gives close attention to a wide range of subtle components of conventional or encoded linguistic meaning, including many that are nontruth-conditional and function to do things like place constraints on the context, on anaphoric reference, on temporal interpretation, and on speech act interpretation. The chapter on information structure is particularly interesting in its attention to prosodic features (contrastive stress, particular intonation contours) and discourse connectives like 'well' and 'however' that play an important role in (linguistically) signalling areas of (dis)agreement between interlocutors. I agree with L\&S that many philosophers of language and pragmaticists in the Gricean tradition give insufficient weight to these rich contributions from linguistic systems and opt for an overly bare-bones semantics, wielding (Modified) Occam's Razor in a fashion that has little bearing on the psychological reality of our linguistic knowledge or indeed of human memory more generally. This is not, however, true of the RT framework, within which generations of researchers have developed accounts of structures, words and morphemes in many different languages, employing what is known as 'procedural semantics', an approach which has been applied to many of the non-truth-conditional components of linguistic meaning that interest L\&S. ${ }^{2}$

However, there is a 'baby with the bathwater' worry with the approach presented in this book, which so drastically reduces the work of pragmatics and dispenses with, or aims to dispense with, the class of conversational implicatures entirely (all the familiar cases are claimed to be either the result of a linguistic convention or, as in figurative uses of language, the effects of imaginative processes that are not instances of speaker meaning). I won't be trying to defend a Gricean account here, or even an RT approach, ${ }^{3}$ although I'll suggest along the way that something like the latter sort of cognitively-based account is often needed in order to infer intended utterance content from the rich (but underdetermining) clues provided

\footnotetext{
2 See, for instance, Blakemore (1987), Wilson \& Sperber (1993), and Escandell-Vidal et al. (2011).

3 See Bezuidenhout (2016) for a thoughtful critique of L\&S's discussion of Relevance Theory.
} 
by the language system. The main aim of this short critical review is to provide evidence, through discussion of specific utterance examples, to support the claim that there are significant pragmatic contributions to the content correctly grasped by an addressee (and thus that pragmatics contributes to the information that is registered on the conversational record).

\section{Cases of pragmatically inferred content}

Let's start with the case of scalar implicature, which so dominates the neo-Gricean literature and which L\&S themselves explicitly consider. Two of the familiar cases involve utterances of the forms 'Some of the X ...' and 'P or Q', which are standardly analysed as conversationally implicating 'Not all of the X ...' and 'Not (P and Q)', respectively:

1. a. 'Mary ate some of the cookies' $\rightarrow$ Mary didn't eat all of the cookies

b. 'John is out with friends or visiting his aunt' $\rightarrow$ John isn't out with friends and visiting his aunt

L\&S maintain that the more specific interpretation here is a matter of linguistic rules or conventions: 'Some of the $\mathrm{X}$ ' is ambiguous between the at least one $X$ meaning and the more specific upper-bounded meaning. The role of pragmatics is, at most, to disambiguate (there is no pragmatic enrichment of semantically given content, and, in particular, no conversational implicature). On this view, the entailment scales that play the pivotal role here, e.g. <some, all>, <or, and>, are lexically stipulated and other linguistic devices (e.g. stress, intonation) may indicate that the stronger reading is the right one. The line of argument is quite 
convincing and a number of other theorists have also opted for a 'conventionalist' account of these standard scalar cases (e.g. Chierchia et al. 2012). ${ }^{4}$

However, the interesting cases for the current issue of pragmatics vs. linguistic convention are those discussed by Hirschberg (1991) as involving 'ad hoc scales' or ordered stages in a process, which seem to support scalar implicature or something very closely akin to it:

2. A: Have you mailed that letter?

B: I'm typing it right now.

$\rightarrow$ B hasn't mailed the letter yet.

3. Frantic husband rushes into maternity hospital and says to nurse:

'I'm late - it'll be a disaster if I've missed the birth.'

[Or perhaps he says nothing, but just rushes up to her looking anxious.]

Nurse: Calm down. She's in the theatre waiting area.

$\rightarrow$ The birth hasn't happened yet, so the husband hasn't missed it.

In (2), the implication depends on the fact that, typically, there are various ordered stages involved in the sending of a letter: formulating it, typing or handwriting it, maybe proofreading and signing it, putting it in an envelope, and getting it into the mail system. In (3), the implication depends on there being stages of giving birth in a particular hospital setting: early labour, hospital admission, getting appropriately gowned and sitting in the waiting area, more advanced labour with admission to the birthing theatre, and so on. These are clearly not cases of lexically provided scales of items, but are entirely to do with general knowledge about how

\footnotetext{
${ }^{4}$ However, see Geurts (2010) for detailed and empirically supported arguments against conventionalist accounts of scalar implicatures.
} 
things work in the world. The inferences drawn hinge on believing that if a person is at one stage of the process they have not yet reached what is typically a later stage. It is straightforward enough to give Gricean rational reconstructions of the derivation of these meanings, employing a line of reasoning very similar to the standard scalar cases, governed by the maxims of quantity and relation (see Hirschberg 1991, Geurts 2010: 31).

These are cases of conversational implicature, as Grice conceived of this construct (Grice 1989), and they make important contributions to the conversation, contributions which one might reasonably think would be recorded on the conversational scoreboard/record. To use L\&S's terminology, they are public contributions to the inquiry at issue and involve certain commitments on the part of the interlocutors. However, given L\&S's strictures, they won't be registered on the scoreboard because they are not wholly a function of linguistic conventions. This looks like a clear problem for their view.

Many post-Gricean pragmatic theorists think there is more to the role of pragmatics in utterance understanding than the derivation of conversational implicatures. In fact, a lot of implicatures, especially (but not only) those initially categorised as 'generalised', have been reanalysed as cases of 'pragmatic enrichment' which contribute to the recovery of the proposition that is taken to have been directly communicated by the speaker ('what is said' in the terms of Recanati (2004), 'explicature' in RT terms). Consider two examples of what can be described as relevance-based, local pragmatic enrichment of truth-conditional content (both taken from Simons (forthcoming)):

4. A: What's making all that noise in the attic?

B: Either there's a nest up there or some squirrels have moved in. [ 'nest' understood to mean occupied (by birds) nest ]

5. A: I'll see you next month at the conference in Boston. 
B: Yes, great. Actually, if I rent a car, would you like to travel with me?

[ 'rent a car' understood to mean rent a car for the purpose of driving it to Boston ]

These are cases of the enrichment of embedded content, which contributes to the proposition expressed (the disjunction in (4) and the conditional in (5)), so they cannot be Gricean implicatures, properly speaking. Simons' primary goal is to show that these can be accounted for by Gricean rational reconstructions of a pretty standard sort, a matter of global reasoning involving the Cooperative Principle and the maxim of Relation. Without going into the details, the reasoning turns on recognising an apparent failure of relevance of the whole complex utterance and locating that failure in a subclause, e.g. in (4), the first disjunct 'there's a nest up there' isn't a fully relevant answer to the question about the source of noise (it is not nests that emit noise but certain occupants of them). ${ }^{5}$

On the face of it, these look very much like cases of pragmatic inferences making a contribution to content, to the public meaning, which on L\&S's account should be tracked on the conversational record. This richer content often influences the linguistic acts of subsequent speakers (e.g. 'That doesn't sound like birds to me' uttered by A in the case of (4), or 'Yes, thanks, but I won't be able to help with the driving as I've lost my license' in the case of (5)), which is one of the key roles envisaged for the conversational record by Lewis (1979). But, again, this content won't be recorded, according to L\&S, because it is not the result of a linguistic convention ('nest' does not have as one of its meanings nest occupied by birds, 'rent a car' does not have as one of its meanings rent a car for the purpose of driving it to Boston).

In fact, there are much simpler cases where some sort of relevance-based pragmatic inference is essential for the recovery of the proposition directly expressed and communicated by a speaker:

\footnotetext{
${ }^{5}$ The relevance-theoretic account would work a bit differently (see Carston forthcoming).
} 
6. a. Mary's picture is the best.

b. Are you ready?

c. The doctor prescribed headache pills and fertility pills.

Relevance theorists and many other pragmaticists would maintain that the linguistically provided content in (6a) and (6b) is patently incomplete as regards truth-conditional content and pragmatic inference supplies the completion. Even those who might dispute that point (e.g. semantic minimalists such as Borg (2004)) would allow that grasping the proposition the speaker is expressing (not merely implicating) here requires the derivation of further content which is a matter of pragmatics rather than of linguistic convention. In (6a), the picture may be a portrait of Mary, it may have been painted by her, just bought by her, her favourite one, the one she pointed at earlier on, the one that haunts her dreams, and so on; in (6b), there must be some more or less specific activity or event his readiness for which the addressee is being asked about (but there are no semantic constraints at all on what that event/activity may be). What the two have in common is the fact that no speaker ever intends to communicate just the invariant meaning that the linguistic forms alone provide. If asked 'Mary's picture in what sense?' or 'ready for what?', it would be absurd for the speaker to respond 'I just mean Mary's picture in some/any sense or other' or 'I just mean: are you ready punkt'. In both cases, the relevant occasion-specific unit of content has to be pragmatically inferred. In (6c), the point is essentially the same but runs a little differently as, arguably, the two compound nominals 'headache pills' and 'fertility pills' are sufficiently conventionalised that a pragmatic inference is not now required. However, the conventionalised relation between 'pills' and the nominal modifier is the opposite in the two cases (to reduce, to increase, respectively) and the more general point about noun-noun compounds is the absence of any constraint on the relation that might hold between them. Consider, for instance, the various 
nominal relations understood for 'sweet shop', 'honey bee', 'mouse mat', 'doormat', 'pontoon bridge', 'birth mark', 'boot camp', and so on and on. Furthermore, it is not difficult to come up with scenarios in which the relation between the head noun and modifying noun is other than the one that has become established (e.g. pills that induce headaches (perhaps for some experimental purpose) and pills that inhibit fertility). This is all a matter of an initial pragmatic inference made in response to a specific contextual goal or concern, with subsequent conventionalisation of the relation inferred. In the absence of a particular context, all we can say about the meaning of the hypothetical nominal compound 'whiskers fork' is that it refers to a kind of fork (the syntax gives us that), which is in some relation to whiskers (it could be made of them, look like them, be used to do something to them, or whatever other possibilities the world allows). ${ }^{6}$

To conclude this section: L\&S have a task on their hands to explain away a range of determinate components of communicated meaning which are significant contributions to the inquiry under discussion and should therefore be entered on the public conversational record, but which are provided by pragmatic inference rather than by linguistic conventions.

\section{Polysemy and pragmatics}

A case that L\&S consider in some detail concerns what is traditionally known as an 'indirect speech act' (Searle 1975), but which L\&S treat as polysemy, that is, as a word or phrase with two (or more) related meaning conventions. They discuss the following example (addressed to a waiter in a restaurant):

7. X: Can I have the French toast?

\footnotetext{
${ }^{6}$ For lively discussion of examples of this sort, I am indebted to John Collins, Stephen Neale and Deirdre Wilson, at the symposium on Lepore \& Stone's Imagination and Convention. Institute of Philosophy, London, $19^{\text {th }}$ May 2015.
} 
This is understood as X placing an order for French toast. According to the traditional analysis, the direct speech act is a question about whether something is possible and the indirect speech act (a conversational implicature) is a request or order (for French toast). According to L\&S, however, the word 'can' is polysemous; it carries two (or more) speech act conventions: (a) the question about possibility, and (b) the placing of an order/request. The role of pragmatics here is (as ever and only) to select the contextually appropriate meaning convention, which is (b) in this instance, and that selection is made on the basis of general knowledge about standard restaurant procedures, without any issue of recovering the speaker's communicative intention. There is no indirect speech act, no pragmatic calculation from the 'literal' question meaning to the implicated request/order. L\&S point out that, in keeping with the conventionality of the placing an order meaning of 'can I?', different linguistic forms are employed in different languages for this purpose; hence there is the element of arbitrariness, which they, along with David Lewis, insist is crucial to the notion of a convention (p.95).

Of course, there are many other ways of using English to place an order in a restaurant:

8. a. I would like the French toast.

b. I'll have the French toast.

c. I'm in great need of some French toast.

d. The French toast (please).

e. The French toast would be great.

f. You can get me the French toast. 
But the variation is actually quite constrained, both the variation in the different speech acts that 'can I?' can be used to express, and in the range of linguistic forms that can be used to express the placing of an order. You can't place an order for French toast by making any old statement about French toast:

9. a. I hear that French toast is eaten a lot by French school-children.

b. French toast is also known as eggy bread or gypsy toast.

It's of interest here to consider why the utterance of some sentences about French toast can constitute the placing of an order while others cannot. Along with the Griceans, I would maintain that the placing an order meaning is calculable from the literal compositional meaning of the utterances in (8) - on the basis of our quite complex understanding of psychosocial relationships that involve wanting others to do things for us, negotiating with them to get what we want, issues that arise from imposing on others, expectations of politeness, etc., and, specifically here, the standard social roles and behaviour of customers and waiters in restaurants. Given this sort of general knowledge, we can see clearly the inferential connection between the literal sentence meanings in (8) and the speech act of placing an order/request, a connection which is missing in the case of the utterances in (9). ${ }^{7}$

So, even if (some of) these are conventional (or semi-conventional) uses and they are not now actually calculated, their origin is a matter of pragmatic inference. As argued in detail within Relevance Theory (Carston 2013, Falkum 2015), polysemy very often has its basis in pragmatics. For instance, the sense of 'drink' as drink alcohol and the sense of 'bachelor' as unmarried man who is eligible for marriage are pragmatically inferred narrowings of the more general senses of drink (liquid) and unmarried man, respectively; the

\footnotetext{
${ }^{7}$ I am going along with L\&S's polysemy analysis here (and arguing for its pragmatic basis), but see Clapp (2015) and Bezuidenhout (2016) for a range of observations that indicate the implausibility of any kind of ambiguity analysis of these kinds of cases.
} 
hyperbolic senses of 'boiling', 'freezing' and 'starving' are pragmatic broadenings of the literal senses and the metaphorical senses of 'angel, 'saint', 'bastard', 'cow', and 'chameleon' can also be explained pragmatically (see Wilson \& Carston 2007 for detailed relevance-based pragmatic derivations). So pragmatics is quite often the source of a linguistic convention, and, in that sense at least, can be (or can have been) a provider of content, not merely an instrument of disambiguation. Lexical meaning evolves and very often it is a (recurrent) pragmatic inference that lies at the root of new meanings; yet it seems that on Lepore \& Stone's account there is no way for pragmatically derived content to get onto the conversational record, as is surely required if that meaning is to acquire the status of a linguistic convention.

According to L\&S, 'Conventionality and calculability must be incompatible. ... Conventions require alternatives, but the existence of alternatives means it would be rational that the conventional case didn't hold, and so, you can't calculate anything from it.' (p. 104). Certainly if a component of utterance meaning cannot be calculated, then it must be conventional - this was Grice's point, I think, in using the calculability requirement as a necessary condition on conversational implicatures and thereby distinguishing them from conventional implicatures. However, if some element of meaning is calculable (can be calculated), it may be derived either pragmatically or via a convention, where the convention is one that has a pragmatic (i.e. calculated) origin.

As I understand it, Lewis allows for various ways in which an instance of new meaning coordination can be achieved (and can, therefore, provide the basis/precedent on which a convention may ultimately become established). As L\&S say, 'For Lewis, conventions are established gradually. At first, coordination succeeds through other mechanisms, like salience, good luck, or partial or tentative precedents' (p.: 252). It is a mystery to me why they do not acknowledge here the role of a pragmatic inferential mechanism in achieving an initial coordination. Setting aside 'good luck', which doesn't seem 
a highly promising mechanism, both 'salience' and 'partial or tentative precedents' would fall within a pragmatic account like that given in relevance theory. Salience is one factor affecting the accessibility of interpretations, the more accessible an interpretation the more likely it is to be assessed for relevance (cognitive implications), and an interpretation selected as optimally relevant on a particular occasion may become a linguistic convention through repeated use and weight of precedent. As Lewis says, some conventions arise implicitly and gradually. That is, there is a process of conventionalisation and conventionalisedness is a matter of degree, so some of these ways of issuing an order/request may be more established, closer to being full-blown conventions, than others.

Finally, recall L\&S's point that there are cross-linguistic differences in the verbal construction used for placing an order in a restaurant. While English speakers often use the 'Can I ...?' expression, speakers of another language might use some other expression, perhaps their language's equivalent of 'It would be pleasing to me if ...'. While this is undoubtedly true, it is not evidence against a pragmatic derivation of the request/order in each case; rather, it may simply reflect differences in the cultural contexts and behavioural norms within which the usage originated. In any of these cases, it can be plausibly argued that there was an original pragmatic inference which resulted in the order/request interpretation.

\section{Lexical innovation and pragmatics}

Some kinds of lexical innovation can occur in communication without any need for explicit announcement that something new is being introduced. Speakers may use existing words in a new sense that is semantically related to its established sense or may coin a new word that is semantically related to an existing word; in both cases, hearers are very often able to pragmatically infer the new sense/word without needing any explicit explanation. Consider, for instance, the following examples of motivated word coinages, cases where an existing 
common noun or a proper name ('porch', 'wrist', 'Houdini') is employed as a verb (taken from Clark \& Clark 1979):

10. a. The boy porched the newspaper.

b. She managed to wrist the ball neatly over the net.

c. The prisoner houdinied his way out of the locked cell.

Focusing on (c): even if you've never encountered this verbal use of the name 'Houdini' before, you'll very likely be able to figure out its intended meaning, provided you have the requisite world knowledge about the man Houdini, specifically that he was renowned for his ability to escape, against the odds, from all sorts of situations of extreme physical confinement. This, again, is a matter of pragmatics and, again, relevance theorists have given accounts of the inferential process involved (driven by the goal of deriving an interpretation which meets a particular standard of relevance). The proposition expressed can be paraphrased as 'The prisoner made an extraordinary escape out of the locked cell'

Once the audience has identified the property the speaker intended to denote with the verb 'houdini', this is public truth-conditional content and should, therefore, go onto the conversational record, although it has involved a local pragmatic process of inferring the concept the speaker intends by her use of 'houdini', i.e. pragmatics has played a role in the delivery of content here, not just in disambiguating. ${ }^{8}$ There is nothing exceptional about this, as the dictionary shows us, with its many instances of both denominal verbs and deverbal

\footnotetext{
${ }^{8}$ Emma Borg (p.c.) has suggested to me that L\&S might claim that this pragmatically inferred meaning doesn't go onto the conversational record, but rather onto whatever record keeps track of imaginatively recovered meaning. But, first, it is far from obvious that this is a case of imaginatively recovered meaning; if it is, it would follow that the utterance has no propositional content (nor even any literal meaning), contrary to apparent fact. Second, it is unclear that there is, or should be, any public record of imaginatively derived effects, given their individual and subjective nature; certainly L\&S give no account of how that kind of meaning is recorded or how it affects the ongoing communicative interaction of speakers.
} 
nouns. These are just two of the many kinds of innovative uses of language which our pragmatic capacities make possible.

L\&S acknowledge the importance of accommodating lexical innovation in their account, but only discuss one sort of case in any detail. This is the introducing of a new proper name, which is quite different from the pragmatically-based innovations I've been discussing. Here is their description of such a case: 'Say somebody announces that they have a new pet dog, called Luna. On Kripke's (1972) understanding, the utterance initiates the audience into a network of causal chains that connect them via the name Luna to that dog.' (p.223). And they claim that part of what's involved in getting onto the conversational scoreboard is that interlocutors take on specific commitments that govern the institution of new meanings: 'Following Kripke (1972), interlocutors must jointly commit to preserve the link between the name and its referent. Or consider a newly-coined general term. Its meaning depends on the joint commitments of interlocutors to triangulate a consistent, useful and natural distinction between the things that satisfy the word and the things that don't.' (p.224)

The cases at issue here (new proper names or new general terms, e.g. 'smanela' for a newly discovered breed of marsupial) are opaque and unmotivated, that is, they are not inferable via pragmatic principles from existing linguistic meaning conventions associated with the word. So there are two importantly distinct sources of new meaning conventions: (i) New proper names and new general terms involve the establishing of a meaning convention in a more or less explicit way (sometimes by overt stipulation); they are introduced with a view to being accepted as regular, stable, established meanings, underpinned by general naming conventions and the commitments we incur to use them consistently. This is not a matter of pragmatics; (ii) The kinds of innovative uses of language that have a pragmatic basis, such as the meaning shifts and motivated word coinings that I've discussed above, do not come with any built-in assumption that a convention is being instituted. They are ad hoc, for the particular occasion of use, and whether conventional meaning does or does not eventuate 
depends on all manner of contingencies of future communicative interactions in the particular language community. Unaccountably, L\&S omit all mention of this latter (predominant) source of new linguistic meaning conventions.

\section{Conceptions of linguistic knowledge}

My main aim in this commentary has been, if not to refute, to raise strong doubt about L\&S's claim that the shared content of utterances is entirely a matter of linguistic and discourse conventions, and the only role played by pragmatics is disambiguation. I've argued that pragmatics can and often does play a content-contributing role in our meaning-making. It can provide audiences with occasion-specific content that is not a matter of linguistic convention, as in the ad hoc quantity implicature cases and the relevance-based enrichments of truthconditional content. It is also one of the primary means by which an initial meaning coordination is achieved when a new linguistic expression or new sense of an existing form is produced, making for a precedent, which, through repeated use, may result in a new meaning convention.

To conclude, I want to touch briefly on a different matter, one that is highly relevant to the appropriate positioning of L\&S's stance within the scientific study of human language. There is a massive and striking disparity between the way L\&S conceive of linguistic knowledge and grammar, and the way these are conceived of by linguists working in the generative grammar tradition (e.g. Chomsky 2000). The operative notion for these linguists is 'I-language', a component of the human mind whose workings are largely inaccessible to consciousness and whose mature state is underpinned by an innately-given species-specific 'language faculty', such that the acquired elements of the system are essentially just a set of constrained parameter-fixing options. As L\&S themselves note: 'Linguists' understanding of the language faculty fits poorly with the assumption that linguistic meaning is conventional in 
Lewis's sense.' (p.244). The linguistic knowledge at issue is simply not a matter of conventions of any sort and certainly does not include such 'know-how' as how to place an order politely in a restaurant or how a discourse is structured.

L\&S are concerned with linguistic behaviour, in particular linguistic communicative behaviour and 'public meaning-making', a social competence. While this behaviour would not be possible without I-language and the unbounded array of meaningful structures it enables, by itself I-language is communicatively inert and, according to many linguists, did not evolve for communication. The linguistic meaning that comes from grammar or Ilanguage simply places constraints on what can be said/communicated, while, on top of it, as it were, there is a great mass of communicative and other social conventions that come into play in the use of language in human interaction. That there are (at least) two different levels of theorising to be distinguished here is especially evident in thinking about 'the' mental lexicon. There are the lexical atoms (or feature bundles) that are the input to the syntax and so part of the I-language, and then there is the array of memorised form-meaning pairs that accumulate in a speech community, including families of related words and senses that are the result of on-line ad hoc pragmatic inferences which have stabilised into shared communicative conventions. ${ }^{9}$ In the long run, what we want is an account of our knowledge of language and its communicative use that properly distinguishes its component parts and their basis: I-language, grounded in our inherent cognitive makeup, is one such component and meaning conventions, many of them grounded in pragmatics, are another.

Department of Linguistics

University College London

\footnotetext{
9 Jackendoff (1997) maintains that the lexicon contains not only words and idiomatic phrases (e.g. 'spill the beans'), but an array of other memorised forms, including conventional greetings, standard collocations (e.g. 'rancid butter', 'beg the question'), names and clichés. These are all shared meaning conventions of the sort that L\&S are concerned with.
} 


\section{References}

Bezuidenhout, A. 2016: What properly belongs to grammar? A response to Lepore \& Stone. Inquiry, 59(2), 175-94.

Blakemore, D. 1987: Semantic Constraints on Relevance. Oxford: Blackwell.

Borg, E. 2004: Minimal Semantics. Oxford: Clarendon Press.

Carston, R. 2013: Word meaning, what is said and explicature. In C. Penco and F. Domaneschi (eds.), What is Said and What is Not, 175-204. Stanford: CSLI Publications.

Carston, R. forthcoming: Pragmatic enrichment: Beyond Gricean rational reconstruction - A response to Mandy Simons. Inquiry

Chierchia, G., Fox, D. and Spector, B. 2012: Scalar implicature as a grammatical phenomenon. In C. Maienborn, K. von Heusinger, and P. Portner (eds.), Semantics: An International Handbook of Natural Language Meaning, III, 2297-331. Berlin: de Gruyter.

Clapp, L. 2015: Review of Lepore \& Stone Imagination and Convention: Distinguishing Grammar and Inference in Language, Oxford University Press. Notre Dame Philosophical Reviews, 2015.08.21.

Chomsky, N. 2000: New Horizons in the Study of Language and Mind. Cambridge: Cambridge University Press.

Clark, E. and Clark, H. 1979: When nouns surface as verbs. Language, 55, 767-811.

Escandell-Vidal, V., Leonetti, M. and Ahern, A. (eds) 2011: Procedural Meaning: Problems and Perspectives. Bingley, UK: Emerald Group Publishing.

Falkum, I. L. 2015: The how and why of polysemy: A pragmatic account. Lingua, 157, 83-99.

Geurts, B. 2010: Quantity Implicatures. Cambridge: Cambridge University Press. 
Grice, H. P. 1989: Studies in the Way of Words. Cambridge, MA: Harvard University Press. Hirschberg, J. 1991: A Theory of Scalar Implicature. New York: Garland.

Jackendoff, R. 1997: The Architecture of the Language Faculty. Cambridge, MA: MIT Press.

Lewis, D. 1969: Convention: A Philosophical Study. Cambridge, MA: Harvard University Press.

Lewis, D. 1979: Scorekeeping in a language game. Journal of Philosophical Logic, 8(3), 33959.

Recanati, F. 2004: Literal Meaning. Cambridge: Cambridge University Press.

Searle, J. 1975: Indirect speech acts. In P. Cole and J. Morgan (eds.), Syntax and Semantics III: Speech Acts, 59-82. New York: Academic Press.

Simons, M. forthcoming: Local pragmatics in a Gricean framework. Inquiry

Sperber, D. and Wilson, D. 1995: Relevance: Communication and Cognition. Oxford: Blackwell.

Wilson, D. and Carston, R. 2007: A unitary approach to lexical pragmatics: Relevance, inference and ad hoc concepts. In N. Burton-Roberts (ed.), Pragmatics, 230-59. Basingstoke: Palgrave.

Wilson, D. and Sperber, D. 1993. Linguistic form and relevance. Lingua 90, 1-25.

\section{Word count:}

5,330 (without references)

5,705 (with references) 